\title{
Representações do mouro em Portugal: ficções, lendas e história
}

\author{
Carla Carvalho Alves
}

Universidade de São Paulo

\begin{abstract}
RESUMO: PERCEBENDO A GRANDE IMPORTÂNCIA DO ELEMENTO MOURO NA CULTURA PORTUGUESA E DESTACANDO AINDA A RELEVÂNCIA DE SE INTRODUZIR TAL ALTERIDADE EM REFLEXÕES ACERCA DA ESPECIFICIDADE CULTURAL E RELIGIOSA NACIONAL, BUSCAMOS, NESSE ARTIGO, DISCUTIR ALGUNS ASPECTOS REFERENTES A ESSA COMPLEXA INTERAÇÃO CONSTITUÍDA AO LONGO DE SÉCULOS DE UMA CONVIVÊNCIA BÉLICA, MAS TAMBÉM HARMONIOSA.
\end{abstract}

ABSTRACT: PERCEIVING THE GREAT IMPORTANCE OF THE MOORISH ELEMENT IN PORTUGUESE CULTURE AND EMPHASIZING THE RELEVANCE OF INTRODUCING THIS ALTERITY INTO REFLECTIONS ON THE CULTURAL AND RELIGIOUS SPECIFICITY OF THE NATION, WE AIM, IN THIS ARTICLE, TO DISCUSS SOME OF THE ISSUES RELATING TO THIS COMPLEX INTERACTION CONSTITUTED OVER CENTURIES OF A BELLIGERENT, BUT ALSO HARMONIOUS, COEXISTENCE.

PALAVRAS-CHAVE:MOURO, CULTURA PORTUGUESA, ALTERIDADE KEYWORDS: MOOR, PORTUGUESE CULTURE, ALTERITY 
termo mouro, utilizado em um sentido amplo para definir os invasores muçulmanos da península Ibérica, refere-se, como exposto a seguir, aos povos de várias origens, mas, sobretudo, aos habitantes islâmicos do norte da África. Conforme anuncia Ana Rita Gaspar Moreira, é possível acompanhar, em diversos autores, "algumas confusões terminológicas" (MOREIRA, 2005, p.78) no que diz respeito à

[...] definição do termo "mouros", que ora identifica os norte-africanos, sobrepondo-se por vezes com pouca clareza à identificação das populações berberes, ora conserva o âmbito lato que detém no uso comum. (MOREIRA, 2005, p. 78)

Gaspar Moreira lembra, um excerto da obra Portugal contra os mouros (s.d), de David Lopes, no qual o autor admite usar o termo "mouros" de forma pouco precisa, pois, segundo Lopes, essa terminologia foi tomada para designar os habitantes da região da Mauritânia, entretanto, o termo referia-se também a outros povos, como os árabes, sírios e persas. E, finalmente, com base em diversas elaborações em torno do referido termo, a pesquisadora conclui o seguinte:

Mouros são afinal, com alguma consistência, as populações muçulmanas: os dominadores árabes, os berberes islamizados, os muçulmanos que se conservam na península depois da conquista cristã ou os que os navegadores vão reencontrar, a partir do século XV, nas suas expedições em África e na Ásia. (MOREIRA, 2005, p. 79)

Há que considerar também, conforme ressalta Moreira, que "o termo 'mouros' é ainda frequentemente utilizado como denominador coletivo das populações que se opõem aos reinos cristãos" (MOREIRA, 2005, p. 77). E é, provavelmente, dessa dimensão bélica, que se constituiu, no imaginário português, uma das principais referências semânticas acerca dos mouros. Conforme ressalta, abaixo, Alexandre Parafita, a formação da nação portuguesa sob o domínio mouro na península terá, certamente, demarcado um sentido de inimizade e antagonismo em relação aos antigos invasores, na memória coletiva do povo português: 
Obviamente, Portugal, que se formou enquanto nação no seio do domínio muçulmano, não podia furtar-se, no seu inconsciente coletivo, a um imaginário construído sob um caudal denso e organizado de referências à tirania do invasor, cumprindo-se assim o princípio de que a memória coletiva sempre arquiva melhor os atos negativos, devastadores e humilhantes, do que os aspectos positivos, harmoniosos e conciliadores da história. (PARAFITA, 2006, p. 23)

Um aspecto inequívoco da influência do contexto bélico, referente ao período de ocupação moura e também da reconquista territorial da península, prevalente ao longo da história portuguesa, pode ser identificado na própria bandeira nacional que, conforme explica Parafita, “[...] apresenta cinco quinas que representam cinco reis mouros mortos na Batalha de Ourique [...]" (PARAFITA, 2006, p. 26). O autor acrescenta, ainda, que os sete castelos componentes da bandeira representariam também "[...] o número de castelos tomados aos mouros por D. Afonso III” (PARAFITA, 2006, p. 26).

Analisando, de modo mais específico, a influência moura na região de Trásos-Montes, em Portugal, Alexandre Parafita apreende duas constatações aparentemente contrastantes: a primeira refere-se às raras menções, no âmbito historiográfico, à presença moura na região; a segunda diz respeito ao abundante número de lendas de mouros mantidas no domínio da tradição oral daquele espaço. Tal desproporção é compreendida, por Parafita, como um mecanismo de compensação do vazio historiográfico pelo preenchimento, de cunho imaginário, através de formas ficcionais e lendárias de expressão oral:

Quanto mais tênues são as referências históricas sobre um determinado fato de contornos marcantes e perversos, mais facilmente o imaginário lhe dá corpo. Assim se explica que no norte interior do País possa haver maior densidade de lendas de mouros do que no sul, onde os muçulmanos tiveram, durante séculos, presença dominante, permanente e generalizada. (PARAFITA, 2006, p. 35)

O autor esclarece que, embora a historiografia não tenha dado conta de tais fatos, há indicadores consistentes da presença e domínio mouros em diversas zonas da região transmontana e que, os muitos flagelos aí ocorridos, como a destruição da Catedral de Santiago de Compostela, teriam encontrado, na expressão oral popular, uma possibilidade de elaboração para aquelas ações per- 
versas e destrutivas, atribuídas aos chamados infiéis. Mas, para além dos fatos específicos relativos à prevalência da dimensão lendária dos mouros na região Norte, evidencia-se também, no contexto nacional português, a mitificação antagonizada desses povos, condicionada aos mecanismos histórico-religiosos.

Haveria, assim, principalmente a partir da Reconquista da Península Ibérica, no século VIII, uma demonização dos mouros, que assumiriam uma carga simbólica de absoluto antagonismo nacional e, principalmente, religioso. Parafita chama a atenção para o "quadro de Identidade vs. Alteridade" (PARAFITA, 2006, p. 44), constituído nesse período: "Daí que, a Reconquista Cristã, iniciada no VIII século, tenha posto o Diabo a encarnar a imagem do "outro", isto é, dos Mouros, e que em muita da sua iconografia estes sejam apresentados com pés de cabra" (PARAFITA, 2006, p. 44).

Uma das expressões da atribuição demoníaca aos mouros pode ser verificada em muitas das lendas, oriundas de um contexto medieval, referentes às mouras encantadas. Há uma recorrência de narrativas folclóricas, que conjugam a sensualidade irresistível das mouras e um precioso tesouro por elas guardado, com um fundo maléfico ou demoníaco, do qual fariam parte. Conforme esclarece Alexandre Parafita,

[...] à luz dessa inspiração, construída no contexto de um imaginário medieval, os mouros, com sua riqueza ou com sua sensualidade (corporizada na figura das mouras) produziriam sobre os humanos um efeito tentador, conduzido pelo demônio, cujo objetivo seria atraí-los ao Inferno. (PARAFITA, 2006, p. 86)

Parafita ressalta, com base na obra de Adalberto Alves, Portugal: ecos de um passado árabe (1999), que mecanismos de atração e repulsão conduzem à relação de alteridade estabelecida entre cristãos e muçulmanos no contexto português. $\mathrm{O}$ autor percebe, da seguinte forma, as intrincadas relações de perigo e fascínio aí implicadas:

Deste fascínio problemático poderão ter germinado no seio do povo os famosos e inquietantes mitos e lendas de mouros, que, se por um lado, revelam amores sofridos, inviáveis entre cristãos e muçulmanas e vive-versa, por outro, traduzem a perigosidade de um painel de seduções latentes na ilusão de tesouros e de outros encantos que o fenômeno árabe alimenta. (PARAFITA, 2006, p. 96) 
Gentil Marques observa que "[...] foram os Árabes os últimos senhores da Península antes dos cristãos, e os que mais profundas recordações deixaram" (MARQUES, 1999, p. 5). Como também afirma o pesquisador, entre tais recordações, a figura da moura encantada seria uma das mais marcantes no imaginário popular, assemelhando-se, por exemplo, às fadas e sereias, pela representatividade e fascínio que elas exercem no contexto lendário ocidental.

Marques reuniu, no III volume das Lendas de Portugal (1999), quarenta e cinco lendas bastante tradicionais, que apresentam mouros e mouras como parte significativa de sua temática. Em muitos desses textos, enfatiza-se o aspecto sensual e sedutor da moura, exercido, principalmente, sobre os homens cristãos. Na maioria das narrativas, a união entre eles é impossível, ocorrendo, inclusive, alguma desgraça, como a perdição religiosa ou a morte do homem seduzido. Em diversos casos, o principal obstáculo à consolidação do casal encontra-se na figura do pai da moura, representante mais evidente da religiosidade muçulmana, conforme esclarece Parafita:

[...] a figura intransigente e opressora do pai (mouro), como entidade soberana zeladora da ideia anticristã, representa, pela quantidade de incidências, o principal obstáculo a uma relação amorosa entre cristãos e mouros. A sua intervenção vai desde encerrar sua filha "ao descobrir as suas inclinações amorosas" (em Suçães, Mirandela), até encantá-la em "bicho horrendo" (no Castelo de Monforte, Chaves) ou numa monstruosa serpente "com uma grande cabeleira" (no Castelo de Algoso, Vimioso), ou ainda encantá-la e mandar decepar o noivo (na Serra de Domingos, Sabrosa). (PARAFITA, 2006, p. 87)

Alexandre Parafita diz que, embora a figuração do mouro e da moura ocupe lugares diferentes no imaginário popular, havendo, de maneira geral, "sentimentos de aversão e ódio em relação ao mouro e de complacência e paixão em relação à moura" (PARAFITA, 2006, p. 102), ambos apresentariam uma dimensão mítica impregnada de magia e encantamento. $\mathrm{O}$ autor rebate, também, as análises que estabelecem uma distinção rígida entre as figurações lendárias dos mouros míticos e dos históricos.

De fato, Parafita traça uma linha coerente que relaciona aspectos factuais advindos dos conflitos históricos entre cristãos e muçulmanos com os atributos fantasiosos inerentes ao universo mítico. O autor chama a atenção ainda 
para o componente ficcional que recairia sobre a própria construção historiográfica, como se pode acompanhar no seguinte excerto:

Quando se reconhece a ideia de "mouros" como sendo habitantes refugiados em locais inacessíveis, subterrâneos, detentores de poderes exóticos e de imensas riquezas (tesouros), possuidores de mesquitas, mas sobretudo inimigos da fé cristã, não se está, desde logo, a admitir uma clara proximidade, ainda que envolta em uma recreação mítica, com essa outra figura que a história reconhece como os invasores da velha Hispânia, vulgarmente designados também por mouros? E não serão hoje também estes, em face da diluição histórica que sobre eles tem recaído, um produto híbrido da realidade e da mitologia? (PARAFITA, 2006, p. 102)

No entanto, se ocorre, de fato, uma contaminação entre os aspectos míticos e historiográficos nas representações ficcionais dos mouros, na tradição oral, a expressão escrita da literatura de temática moura parece, em alguns casos, partir da figuração desse elemento, em sua vertente histórica, para, então, promover uma significação mais simbólica, ou mesmo mítica, associada ao tema. Assim, ao longo do panorama literário português, desde Fernão Mendes Pinto e Luís de Camões, passando pelos romances históricos oitocentistas, chegando à contemporaneidade, é possível verificar uma gama diversificada de representações de mouros, relacionadas a contextos históricos específicos, mas que alcançam, também, uma dimensão mais abstrata associada a uma alteridade ancestralmente constituída. Relacionado a isso, de alguma forma, percebe-se, ainda, que a figuração do elemento mouro em muitas dessas obras suscita, como veremos adiante, reflexões interessantes sobre a própria cultura portuguesa.

Tangenciando tal perspectiva, identifica-se, em outros casos, a presença moura como uma estrutura mítica autônoma, atuante no contexto cultural e, consequentemente, no discurso literário português, descolada dos fatos históricos oficiais. É o caso, por exemplo, do seguinte excerto de Os fidalgos da casa mourisca, de Júlio Dinis, obra publicada pela primeira vez em 1871. Aqui, o interesse deve-se, justamente, à frustração da expectativa, apresentada pelo título do romance, de uma provável presença de elementos mouros em seu enredo. A razão do não cumprimento dessa expectativa é já introduzida nos primeiros parágrafos da narrativa, como se pode acompanhar a seguir: 
A tradição popular em Portugal, nos assuntos de história pátria, não se remonta do período da dominação árabe nas Espanhas.

Pouco ou nada sabe o povo de celtiberos, de romanos e visigodos. É, porém, entre ele, noção corrente que, em outros tempos, fora este país habitado por mouros, e que só à força de cutiladas e de botes de lança os expulsaram os cristãos para as terras da Mourama. (DINIS, s.d, p.899).

Após dissertar sobre vários indícios da memorial presença moura no país, como "os romances nacionais", que contemplavam as lutas entre os heroicos portugueses e os invasores árabes, os "contos narrados em volta da lareira" sobre as mouras encantadas, os tesouros enterrados por mouros e ainda por encontrar (DINIS, s.d., p. 899), o autor, finalmente, explica o aparente descompasso entre o título e o conteúdo do romance:

Esta mesma noção histórica do povo é que dá lugar a outro frequente fato. Quando, no centro de qualquer aldeia, se eleva um palácio, um solar de família, distinto dos edifícios comuns por uma qualquer particularidade arquitetônica mais saliente, ouvireis no sítio designá-lo por nome de Casa Mourisca, e, se não se guarda aí memória da sua fundação, a crônica lhe assinará infalivelmente, com data, a lendária e misteriosa terra dos mouros. Era o que se sucedia com o solar dos senhores Negrões de Vilar de Corvos, que, em três léguas em redondo, eram conhecidos pelo nome de fidalgos da Casa Mourisca. Não se persuada o leitor de que possuía aquele solar feição pronunciadamente árabe, que justificasse a denominação popular, ou que mãos agarenas houvessem de feito cimentado os alicerces da casa denominada assim. (DINIS, s.d., p. 899)

Tal colocação assemelha-se, bastante, ao seguinte comentário elaborado por Leite de Vasconcelos sobre o assunto: "O povo, cuidando que antes dos mouros ninguém existia, serve-se da palavra mouro para designar, não só os monumentos arruinados, mas também os que oferecem uma aparência estranha" (VASCONCELOS, 1999, p. 5). É notável, nas duas elaborações, o esvaziamento do caráter factual referente à presença árabe em Portugal e uma arbitrária associação entre os elementos discordantes do padrão cultural comum.

Pode-se verificar, ainda, em pelo menos um caso, que a utilização simbólica do mouro, designativa da alteridade, contaminou também a literatura brasi- 
leira. Referimo-nos à obra de José de Alencar, $O$ guarani. A inserção de uma cantiga referente à relação afetiva entre um mouro e uma cristã, conforme apresentado abaixo, parece-nos, de fato, bastante significativa:

Aos pés daquela a quem ama / Jurou / Ser fiel a sua dama.

A gentil dona e senhora/ Sorriu; / Ai! Que isenta ela não fora!

"Tu és mouro; eu sou cristã." / Falou / A formosa castelã.

"Mouro, tens o meu amor, / Cristão, / Serás meu nobre senhor."

(ALENCAR, 2000, p. 289)

A importância dessa referência deve-se, principalmente, ao contexto retratado nessa obra de Alencar, em que se apresenta a relação entre brancos e índios em um Brasil seiscentista, no qual, surpreendentemente, como em outras obras do autor, o elemento negro é obliterado. Ou seja, a presença do mouro faz-se tão incisiva no imaginário lusófono, como alteridade religiosa e cultural, que, mesmo uma obra canônica, de cunho nacionalista, que elege, apenas, o componente indígena e branco, como fundadores da nacionalidade brasileira, retoma o mouro para metaforizar o índio.

No caso, o índio mencionado na cantiga de Cecília poderia ser entendido como uma alusão ao personagem Peri, que não se submetera ao cristianismo. Essa analogia simbólica, entre o mouro e o índio, apreendida do texto de Alencar, talvez se tenha viabilizado justamente devido ao lugar distanciado e quase mítico assumido pelo elemento indígena na cultura brasileira oitocentista, semelhante ao contexto lendário ocupado pelos mouros no imaginário português.

$\mathrm{E}$, realmente, segundo Boxer, o confronto estabelecido entre portugueses e mouros, no período colonial, parece ter influenciado, posteriormente, as relações dos colonizadores lusitanos com os povos colonizados. Para o autor de $A s$ relaçoes raciais no império colonial português, o marco inicial da expansão ultramarina, “a captura do forte mouro em Ceuta, 1415” (BOXER, 1967, p. 37), foi decisivo na forma como, posteriormente, os portugueses interagiram com os povos submetidos. Daí, talvez, a contiguidade estabelecida entre os mouros, representantes de uma alteridade simbólica para os colonizadores portugueses, com o índio, que assumiria um papel semelhante para os brasileiros.

Os Lusíadas apresentam-se como obra exemplar para se observar esse confronto entre portugueses e mouros no âmbito da expansão. A percepção 
preconceituosa e redutora dos cristãos em relação aos muçulmanos traduzse aí em expressões pejorativas como, "torpe Ismaelita" (CAMÕES, s.d., p. 55), "bárbaro Gentio” (CAMÕES, s.d., p. 57), "cães” (CAMÕES, s.d, p. 74), "bruta gente" (CAMÕES, s.d., p. 76), apenas para citar algumas das formas como são retratados os africanos seguidores de Maomé. Ressaltando, especificamente, esse aspecto contido na obra épica de Camões, António José Saraiva faz o seguinte comentário: "Os Lusíadas exprimem [...] a afetação de um civilizado 'ocidental' perante os 'bárbaros'” (SARAIVA, 1996, p. 98).

Por outro lado, Saraiva destaca a obra de Fernão Mendes Pinto, que apesar de estar também localizada no âmbito da expansão colonial portuguesa relativiza e até mesmo inverte a identificação do povo português com a civilização e a caracterização bárbara dada aos orientais:

Fernão Mendes Pinto inclina-se até o polo oposto ao de Camões ao ver nos orientais qualidades de civilização que faziam que em relação a eles os Portugueses fossem os verdadeiros bárbaros. (SARAIVA, 1996, p. 98)

De maneira geral, pode-se dizer que Saraiva identifica em Os Lusíadas uma perspectiva contrária ao padrão corrente, no que se refere à forma como os portugueses se relacionavam com os povos por eles colonizados ou com os quais mantiveram algum tipo de contato. Em uma abordagem semelhante à de Gilberto Freyre (Casa-grande \& senzala), o autor de A cultura em Portugal destaca, no comportamento dos portugueses,

[...] uma certa liberdade em relação às fronteiras culturais, uma certa promiscuidade entre o Eu e o Outro, uma certa falta de preconceitos culturais, a ausência do sentimento de superioridade que caracteriza, de modo geral, os povos de cultura ocidental. (SARAIVA, 1996, p. 98)

Para António José Saraiva, essa seria, ainda, a explicação para o fato de os mouros, assim como os judeus e negros que ficaram em Portugal, terem "desaparecido", para ele, isso "só se explica por terem sido assimilados pela maioria branca" ao invés de se isolarem em ghettos (SARAIVA, 1996, p. 98).

Conforme vimos anteriormente, todavia, o contexto relativo às relações amorosas entre portugueses e mouros parece ter constituído elaborações len- 
dárias bastante conflituosas no imaginário lusitano. Em uma perspectiva generalizante, pode-se dizer que a sedução da mulher moura pelo português é concebida como um evento positivo, um tipo de submissão e conquista, que talvez tenha como fundo uma analogia com a própria conquista territorial. Por outro lado, a relação amorosa da mulher portuguesa com o mouro é caracterizada, de modo geral, como uma ação imoral, vinculada a um contexto de traição, que culmina, em muitos casos, com a punição fatal de ambos. Abaixo, um caso bastante paradigmático dessas conturbadas relações amorosas entre muçulmanos e cristãos com os componentes de traição, vingança, poder e submissão aí implicados:

Foi certamente Ramiro que deixou um rasto lendário, recolhido nos livros de linhagens portugueses. Ele, segundo a lenda, matou o rei mouro Gaia, que lhe tinha roubado a mulher; matou também a mulher, que o havia atraiçoado com o mouro, e casou com uma moura chamada Artiga, que no batismo mudou o nome para Aldara. Deste casamento nasceu Albozar, grande conquistador de terra aos Mouros, à volta do Porto e entre o Douro e o Mondego. (SARAIVA, 1996, p. 22)

Essa temática foi também desenvolvida por Almeida Garrett, no início de suas atividades literárias, com o poema Dona Branca. A obra retrata o rapto de D. Branca pelo chefe mouro Aben-Afan e uma posterior relação afetiva entre eles. Também aqui ocorre a punição do mouro: Aben-Afan, que ousara se relacionar com uma mulher cristã, é morto em um combate com os cristãos. Apresenta-se, ainda, o sofrimento trágico de D. Branca, que acaba enlouquecendo após a morte do amante.

O poema recorre também a muitos fatos do repertório fabular acerca dos mouros, como o caso de Oriana, uma moura encantada, abarcando, ainda, episódios de magia e ressurreição de mortos, entre outros. Entretanto, para além dessa disposição previsível cumprida ao longo do poema, observa-se uma reflexão sobre o caráter bárbaro dos próprios europeus, como se pode acompanhar abaixo:

Culpas, Europa, o muçulmano bárbaro?

$\mathrm{E}$ os teus cárceres negros e traidores, 
Onde à inocência cândida, à piedade

Arma pérfido bonzo o laço astuto,

Laço, que, eterno, a vida, os gozos dela,

A ventura, o prazer de um nó separa?

Corta sem dó - cruéis! - e até cerceia

O derradeiro bem de um desgraçado,

$[\ldots]$

[...] - Homem bárbaro,

Ingrato e desleal, qual é o seu crime?

(GARRET'T, 1963, p. 483)

Nessa espécie de digressão, podemos apreender a denúncia de uma prática europeia bastante hipócrita, que localiza no muçulmano apenas as características de um comportamento bárbaro. O poema, após descrever atitudes violentas e cruéis praticadas também pelos europeus com as mulheres escravizadas, designa, finalmente, o europeu como o verdadeiro "Homem bárbaro".

No século XIX, e possivelmente em toda a Literatura Portuguesa, é Alexandre Herculano o grande depositário da cultura medieval e, com ela, da temática moura. Ao longo de quase toda a sua ficção histórica são notórias as referências à presença moura na Península Ibérica. Tanto em Eurico, o presbitero, como em $\mathrm{O}$ bobo, $\mathrm{O}$ monge de Cister e em vários contos que integram as Lendas e Narrativas, os mouros são representados de forma coletiva, nos exércitos muçulmanos, ou individualmente, como personagens secundários (à exceção de "O Alcaide de Santarém”), cuja representação suscita reflexões importantes para se pensar o seu lugar no interior da cultura portuguesa.

Percebe-se, de fato, no conjunto da obra herculaniana, predominantemente voltada para o período medieval, quando se deu a ocupação moura em Portugal, diferentes figurações desses povos. Essa fluidez identificada na concepção literária dos mouros parece, mesmo, justificar-se pela ausência de um repertório factual referente à ocupação árabe em Portugal e à superabundância de elaborações fantasiosas relacionadas ao assunto. A diversidade de formas como são retratados os invasores muçulmanos parece propiciar também nas obras literárias de Herculano perspectivas bastante complexas e diversificadas para se pensar a própria especificidade cultural portuguesa. 
Já no final do século XX, duas obras, particularmente, parecem bastante significativas para se refletir sobre a figuração do mouro na literatura portuguesa: o romance de Mário de Carvalho, Um deus passeando pela brisa da tarde (CARVALHO, 1997), e a celebrada obra de José Saramago, História do cerco de Lisboa (SARAMAGO, 2004). Pontuaremos, a seguir, brevemente, apenas dois episódios representativos da maneira como tal tema é elaborado nas obras mencionadas.

Em determinado ponto da narrativa de Mário de Carvalho, no qual se discute a invasão dos mouros a uma província da Lusitânia, um dos personagens, ao refletir sobre a origem desses invasores, faz a seguinte colocação: "Tudo a mesma gente: púnicos, mouros... Farinha do mesmo saco. O lado errado do Marenostro." (CARVALHO, 1997, p. 23). Nota-se aqui e, de forma mais consistente, no enunciado do romance como um todo a generalização no tratamento do outro, ou daqueles que não pertencem ao Império Romano: os chamados povos bárbaros.

É interessante pensar que o referido romance de Mário de Carvalho, publicado em 1994, e cujo tempo ficcional corresponde ao II século da era cristã, eleja como parte de sua temática a presença dos mouros na região da Lusitânia. A peculiaridade da questão assenta-se sobre o fato de que, nesse período, evidentemente, ainda não existia a religião muçulmana e, portanto, o conflito entre lusitanos e mouros não tinha o peso da motivação religiosa. E, se há uma equalização desdenhosa dos estrangeiros, considerados como bárbaros, são apenas os mouros, aqueles que, de fato, são retratados na obra. Ou seja, se "o lado errado do Marenostro" é sempre o outro, o mouro parece ser o principal representante dessa alteridade no imaginário português. Poderíamos entrever, nessa obra de Mário de Carvalho, a sugestão de uma prevalência árabe na cultura portuguesa que, para além dos fatos históricos e religiosos, alcançaria uma dimensão simbólica propícia para se designar o outro - bárbaro, invasor, exótico, diferente.

Já a citação abaixo, retirada do romance de José Saramago, História do cerco de Lisboa, contém uma expressão que nos parece bastante afinada com a perspectiva acima apresentada. Essa obra, publicada em 1989, contém referências à tomada de Lisboa pelos portugueses, em 1147, então ocupada pelos mouros. Mas, destacamos aqui, especificamente, o seguinte excerto:

[...] é possível que a senhora Maria tenha dito, Há mouro na costa, expressão histórica e popular duma substancial desconfiança originada nos tempos em 
que os mouros, já então varridos da terra portuguesa, vinham assolar as nossas costas e vilas marinheiras, e hoje reduzida a mera reminiscência retórica, porém de alguma utilidade, como acaba de ver-se. (SARAMAGO, 2004, p. 217)

Percebe-se, a partir disso, que a figura do mouro, sempre associada ao perigo iminente, está tão entranhada no referencial luso que, mesmo se desvinculando da significação histórica, ainda atua no discurso popular, como uma "reminiscência retórica", representativa da desconfiança em relação ao desconhecido, qualquer que seja ele.

As complexas e variadas representações do elemento mouro na cultura portuguesa parecem, de fato, alcançar uma dimensão ainda mais abrangente na contemporaneidade. Se no contexto atual acompanhamos conflitos e discussões acerca de identidades nacionais e religiosas, em que, não raro, muçulmanos e cristãos continuam ocupando polaridades antagônicas, a cultura portuguesa, particularmente em sua vertente literária, parece sugerir outra maneira de se elaborar tais relações. A falta de um lastro historiográfico consistente que, em determinado período, propiciou a formação de um corpus lendário e simbólico sobre os invasores muçulmanos parece ter viabilizado para a posteridade possibilidades mais abstratas e abrangentes de se retratar tal relação de conflito. Assim, a literatura contemporânea parece ter extraído da tradição folclórica os contornos pouco precisos do termo mouro que permitem a compreensão de uma gama diversificada de alteridades. Desse modo, o enfoque referente ao conflito entre identidades distintas parece deslocar-se para uma abordagem de espelhamento entre tais identidades, na medida em que o elemento mouro atua como símbolo de uma alteridade esvaziada de especificidades religiosas, nacionais ou culturais. Concluímos, então, que a presença belicosa dos mouros ao longo da história portuguesa perpassou figurações culturais bastante diversificadas, mas quase sempre demarcadas por um viés fictício. A literatura contemporânea, particularmente, parece expressar a maturidade de tal processo significativo contemplando os mecanismos de espelhamento projetados nessa relação de identidade e alteridade. 


\section{Referências Bibliográficas}

ALENCAR, José de. O Guarani. Apresentação e notas Eduardo Vieira Martins. São Paulo: Ateliê Editorial, 2000.

ALVES, Adalberto. Portugal: Ecos de um Passado Árabe. Lisboa: Instituto Camões, 1999.

BOXER, C. R. Relações Raciais no Império Colonial Português: 1415 - 1825. Rio de Janeiro: Tempo Brasileiro, 1967.

CAMÕES, Luís de. Os Lusíadas. São Paulo: Luso-Brasil, [s.d.].

CARVALHO, Mário de. Um deus passeando pela brisa da tarde. Lisboa: Editorial Caminho, 1997.

DINIS, Júlio. Os fidalgos da casa mourisca. In: Obras de Júlio Dinis. v. I. Porto: Lello \& Irmãos, s.d., p. 897 - 1229.

FREYRE, Gilberto. Casa-grande \& senzala. São Paulo: Record, 2000.

GARRETT, Almeida. Dona Branca. In: Obras de Almeida Garrett. v. II. Porto: Lello \& Irmãos, 1963.

HERCULANO, Alexandre. Obras Completas. Introdução e revisão de Vitorino Nemésio. Amadora: Livraria Bertrand, 1979. p. VII - LV.

MARQUES, Gentil. Lendas de Portugal: lendas de mouras e mouros. v.3. Lisboa: Âncora Editora, 1999.

MOREIRA, Ana Rita Gaspar. Árabes e Nação na periferia da Europa: de Alexandre Herculano a David Lopes. Apresentada como dissertação de mestrado em Ciências Sociais - Instituto de Ciências Sociais da Universidade de Lisboa, Lisboa, 2005.

PARAFITA, Alexandre. A Mitologia dos Mouros. Canelas: Gailivro, 2006.

SARAIVA, António José. A cultura em Portugal. Teoria e História. v. II. Introdução geral à Cultura Portuguesa. Lisboa: Gradiva, 1996.

SARAMAGO, José. História do cerco de Lisboa. São Paulo: Companhia das Letras: 2004.

Recebido em 19/02/2011 e aprovado em 10/04/2011. 